\title{
Cultura Acústica e Letramento em Moçambique : em busca de fundamentos para uma educação intercultural
}

José de Sousa Miguel Lopes

Pontifícia Universidade Católica de São Paulo*

\begin{abstract}
Resumo
0 autor parte da caracterização de uma cultura acústica, como a moçambicana, para, em seguida, fazer uma análise da importância das línguas maternas, um dos atributos culturais mais significativos de um povo. Para melhor contextualizar a temática que se propõe desenvolver, o autor apresenta, em traços bastante gerais, alguns dados históricos, políticos e sociais de Moçambique. Em seguida, indaga em que medida o poder político saído da independência levou em consideração os traços fortes da oralidade presentes nesta cultura, e de que modo tal política influenciou, ou não, o processo de letramento. A adoção da língua portuguesa como língua de ensino e a conseqüente rejeição, por parte do poder político, do estudo, sistematização e introdução das línguas moçambicanas nas primeiras séries, têm contribuído para o agravamento das taxas de analfabetismo e para perdas, quem sabe, irreversíveis das tradições orais, ao mesmo tempo que constitui uma desvalorização das várias culturas étnicas. A solução preconizada estará na introdução de um bilingüismo. Isto implica a transformação da língua de oralidade em língua escrita e a conservação de uma língua estrangeira como segunda língua. Esta segunda língua, sendo língua oficial, terá um papel importante em muitas áreas sociais, como a comunicação oficial do Estado, os contatos internacionais etc.
\end{abstract}

\section{Palavras-chave}

Cultura Acústica - Letramento - Educação Intercultural Memória Coletiva.

\section{Correspondência para:}

Rua Bahia, 1010/801 - Centro

30160-011 - Belo Horizonte - MG

email: miguel-lopes@uol.com.br

* Doutorando. 


\title{
Acoustic Culture And Literacy in Mozambique : searching for the basis for an intercultural education
}

José de Sousa Miguel Lopes

Pontifícia Universidade Católica de São Paulo*

\begin{abstract}
The author starts from a characterization of an acoustic culture, such as the Mozambican, to then analyze the importance of mother tongues as one of the most significant cultural attributes of a people. To put the theme to be developed in its context, the author presents in broad lines some social, political and historical information about Mozambique. Next, he discusses in what measure the political power after Mozambique's independence took into account the strong unwritten features that are present in that culture and in what way such policies have or have not influenced the literacy process. The adoption of the Portuguese as the teaching language, and the refusal by the political authorities to research, systematize and introduce the Mozambican languages on the initial grades have contributed to raise illiteracy rates, and to perhaps irreversible losses of oral traditions. At the same time, it constitutes a devaluation of the various ethnic cultures present in Mozambique. The author argues that a solution will be found in the adoption of bilingualism. That implies transforming the oral languages in written languages, and the preservation of a foreign language as the second language. That second language, being the official language, would have an important role in various social areas such as in official communications of the State, in international affairs etc.
\end{abstract}

\section{Key words}

Acoustic Culture - Literacy - Intercultural Education Collective Memory.

\footnotetext{
Correspondence:
}

Rua Bahia, 1010/801 - Centro

30160-011 - Belo Horizonte - MG

email: miguel-lopes@uol.com.br

* Ph. D. Student. 
A essencialidade da comunidade nacional chamada Moçambique parece assentar numa cultura fundamentalmente acústica. 'Designamos por cultura acústica a cultura que tem no ouvido, e não na vista, seu órgão de recepção e percepção por excelência. Trata-se, no entender de Antonio Viñao Frago, de uma "cultura não linear, mas esférica” (1993, p.19). ${ }^{2}$ Numa cultura acústica, a mente opera de um outro modo, recorrendo (como artifício de memória) ao ritmo, à música e à dança, à repetição e à redundância, às frases feitas, às fórmulas, às sentenças, aos ditos e refrões, à retórica dos lugares-comuns técnica de análise e lembrança da realidade - e às figuras poéticas - especialmente a metáfora. Sua oralidade é uma oralidade flexível e situacional, imaginativa e poética, rítmica e corporal, que vem do interior, da voz, e penetra no interior do outro, através do ouvido, envolvendo-o na questão. Nessa cultura, os homens e mulheres sabem escutar e narrar, contar histórias e relatar. E isto com precisão, claridade e riqueza expressiva. De um modo cálido e vivo, como a própria voz. São mestres do relato, das pausas e das brincadeiras, da conversa e da escuta. Amam contar e ouvir histórias, tomar parte nelas.

Mas de que modo, no pós-independência, a política lingüística adotada pelo poder político levou em consideração os traços fortes da oralidade presentes nesta cultura acústica? Em que medida tal política influenciou, ou não, o processo de letramento ? $^{3}$ Às elevadas taxas de analfabetismo herdadas do período colonial (mais de 95\%), vieram somar-se, com o passar dos anos, as preocupantes taxas de evasão e repetência, sobretudo, nas primeiras séries da escolarização formal e no processo de erradicação do analfabetismo no seio de jovens e adultos. Diversos estudos têm mostrado que, desde a independência, a adoção da língua portuguesa como língua oficial e língua de ensino e a conseqüente rejeição, por parte do poder político, do estudo, sistematização e introdução das línguas moçambicanas nas primeiras séries (ainda que a título experimental), tem contribuido para o agravamento das taxas de analfabetismo. Mas mais do que isso, a rejeição desse rico universo lingüístico pode estar contribuindo para perdas irreversíveis das tradições orais, ao mesmo tempo que constitui um desrespeito e uma desvalorização das várias culturas étnicas.

0 que pode acontecer, a longo prazo, se se mantiver tal política lingüística? Não ocorrerão perdas significativas na memória coletiva? Extinguir-se-ão algumas ou uma grande parte das línguas moçambicanas? Em resultado da atual política de homogeneização cultural, não se ampliarão as tensões étnicas, provocando clivagens no tecido social moçambicano?

Que saídas para problemas tão complexos? 0 que se deverá implantar em termos lingüisticos? Poderá a introdução de um

1. Esta conceituação, aplicada de forma genérica às mais de duas dezenas de grupos étnicos moçambicanos, não significa que desconheçamos e/ou desvalorizemos outros sistemas de "escritura", mais próximos da representação pictográfica e ideográfica, como os encontrados até hoje na sua pintura geométrica facial e sobre os artefatos de sua cultura material.

2. Expressões como cultura oral, cultura ágrafa, cultura sem escrita, cultura não-letrada, cultura oralista, cultura de oralidade primária, cultura de forte tradição oral, cultura verbo-motora, entre outras, são utilizadas por vários autores com um significado equivalente ao de cultura acústica. Embora no decorrer de nosso trabaIho possamos utilizar também algumas dessas expressões, parece-nos ser mais adequada a expressão cultura acústica. Essa expressão poderá ser entendida como uma simples metáfora para indicar propriedades de uma cultura que se apóia fundamentalmente no som, no oral, em que a escrita é pouco utilizada. É uma conceituação muito próxima à utilizada por Walter $0 \mathrm{ng}$, ao referir-se às culturas verbo-motoras, nas quais, por contraposição às da alta tecnologia, as vias de ação e as atitudes ante as várias questões dependem muito mais do uso das palavras e, portanto, da interação humana, e muito menos do estímulo não-verbal (predominantemente visual) do mundo "objetivo" das coisas (ONG, 1993, p.72). Eric Havelock utiliza o termo acústico, para se referir às convenções comuns da língua que se acham codificadas em nossos cérebros, que ele considera serem acústicas e não visuais (Havelock, 1996, p.59).

3. A concepção de letramento que perfilhamos é a defendida por Magda Soares. Segundo ela , letramento "é o resultado da ação de ensinar ou de aprender a ler e escrever; o estado ou a condição que adquire um grupo social ou um indivíduo como conseqüência de ter-se apropriado da escrita" (Soares, 1996, p.85). 
bilingüismo abrir caminho a uma revalorização da(s) cultura(s) acústica(s) e, conseqüentemente, das línguas moçambicanas, sem prejuízo para o fato de que, em inúmeras funções, a língua portuguesa continue desempenhando o papel de língua oficial? Que desenho para uma educação intercultural cada vez mais efetiva?

Estas são algumas das questões que nos propomos analisar neste trabalho.

\section{Uma microrradiografia da sociedade moçambicana}

A atual formação social moçambicana é uma sintese complexa de um longo processo de transformação das formações sociais existentes na região austral da África - cujo desenvolvimento endógeno foi impedido pela penetração e dominação colonial -, da formação social colonial estabelecida no território delimitado como Moçambique, além dos valores novos forjados tanto no processo revolucionário de libertação nacional, como na sociedade, resultando em luta por assegurar a formação da nação e um processo de desenvolvimento independente.

Ainda que de forma breve, vejamos, agora, o país, por meio de alguns dados estatísticos. ${ }^{4} \mathrm{~A}$ taxa de crescimento per capita tem decaído desde 1990 e tornou-se negativa a partir desse mesmo ano. Em 1991, o total da dívida externa era equivalente a mais de $350 \%$ do PNB (a segunda maior do mundo, depois da Nicarágua). Este alto nível de dívida constrange a economia de três formas: 1) constitui uma drenagem importante das preciosas divisas de Moçambique; os pagamentos devidos em 1991-1992 montavam a $150 \%$ das receitas totais do país em moeda externa; 2) os pagamentos são feitos a partir do orçamento nacional, reduzindo o montante disponível para serviços públicos; em 1993, só o pagamento dos juros, importava em $1 / 6$ do orçamento nacional; 3) esta drenagem da economia serve como desincentivo do investimento privado, retardando ainda mais o crescimento econômico a curto e a longo prazos.
No campo educacional, em virtude da guerra, 60\% das escolas foram destruídas, tendo, por exemplo, a província de Tete perdido $95 \%$ das escolas. Em todo o país, o regresso de um milhão e meio de refugiados e de quatro milhões de pessoas deslocadas internamente trouxe um aumento de $25 \%$ da população em idade escolar para a escola primária. Somente uma em 12 crianças que entram para a escola primária completam cinco anos com êxito. Esse aumento massivo da procura de serviços educativos, a manterem-se as taxas de ingresso então prevalecentes, necessitaria de um aumento de 30\% dos gastos correntes (1993-1995). A taxa bruta de ingressos no ensino primário caiu de 75,5\% para 43,9\%, entre 1981 e 1992 . A taxa de repetência (27\%) está muito acima da média da África subsaariana (18\%) e dos países menos desenvolvidos (15\%). Enquanto os rapazes obtêm uma média de apenas 2,1 anos de escolaridade, as moças obtêm só a metade deste valor. A relação aluno/professor, em nível nacional, de 57:1 é muito elevada e compara-se, desfavoravelmente, com a cifra para a África subsaariana (41) e para os paises menos desenvolvidos (45). Com a elevada taxa de desistência e, por conseqüência, um número cada vez menor de alunos em anos sucessivos, a relação aluno/professor nos primeiros anos de escolaridade é, segundo os autores do estudo que estamos utilizando, superior a 80:1, em nível nacional, e mesmo mais elevada em algumas regiões. A maioria das escolas funciona num sistema de 2 a 3 turnos. Os gastos com os materiais de ensino e aprendizagem, incluindo os custos dos manuais escolares (90\% do total), são cerca de US\$1 por aluno por ano. Apenas 50\% dos manuais escolares produzidos chegam às mãos dos alunos, sugerindo que US\$1 é uma sobreestimativa do

4. Todos os dados estatísticos que serão apresentados neste ponto têm como fonte WUS (World University Service-UK) / INDE, 1994. 
valor dos materiais na sala de aulas. Os níveis salariais dos professores são excessivamente baixos, deixando a maioria com um rendimento familiar per capita equivalente a oitenta dólares por ano.

Moçambique vivenciou, nas últimas três décadas, um sucessivo processo de rupturas político-sociais de desigual intensidade, é certo, mas que constituíram outros tantos desafios à capacidade criativa e à busca de soluções para os complexos problemas que emergiram após cada ruptura, tanto no campo político, econômico e social, quanto no campo educacional e cultural. Retomando de forma sintética o que ocorreu nesse passado recente e tomando como ponto de partida o ano de 1962, ano da criação da Frente de Libertação de Moçambique (primeira ruptura), que viria a desencadear uma luta armada de libertação nacional contra o colonialismo português até a independência do país em 1975 (segunda ruptura). Na primeira década de independência, o país encetou um projeto de construção de caráter socialista, projeto que, com o posterior alastramento da guerra e a deterioração da economia, acabou sendo sufocado. A gravidade da situação acabou levando o país a adotar a filosofia neoliberal, aderindo, em 1985, ao FMl e ao Banco Mundial como forma de suster a deterioração econômica (terceira ruptura). 0 término da guerra e abertura ao multipartidarismo culminaram com as primeiras eleições gerais multipartidárias de Moçambique, em Outubro de 1994 (quarta ruptura). Um novo quadro de pós-guerra se desenha, no qual o aprofundamento da cidadania e do aprendizado democrático constituem novos desafios para a Frelimo e para a sociedade moçambicana como um todo.

A crise econômica que Moçambique vem atravessando, em resultado dos erros na concepção e direção da estratégia econômica, da guerra de desestabilização e da conjuntura econômica internacional desfavorável, tem aprofundado a dependência. 0 país depende, hoje, de donativos e empréstimos estrangeiros para financiar as importações essenciais e até o próprio orçamento e funcionamento do Estado. Nessa situação, não é fácil salvaguardar-se a soberania nacional, tão necessária à tomada de decisão sobre as mudanças ou reajustamentos econômicos e políticos em curso, correndo-se, assim, um grande risco de se perder, com a adoção de novas políticas econômicas e financeiras, o que tantas vidas custou na luta pela independência nacional. Com a paz alcançada em 1993, o país passou a trilhar o caminho de um sistema sócio-econômico e político com base no multipartidarismo e no mercado.

0 país não está imune à "conflituosidade" étnica. Tal "conflituosidade", decorrente de questões de ordem linguística, e não só, está latente em Moçambique. Com relativa freqüência, os principais órgãos de informação moçambicanos nos dão conta dela. A título de exemplo, o jornal "Domingo", de 22/09/96, que se publica em Maputo, capital do país, refere três notícias que de algum modo têm a ver com esse tipo de "conflituosidade".

Uma notícia, a que foi dado o título de “Alarme do Episcopado Católico", informa que na Carta Pastoral, emitida após recente Conferência Episcopal, os bispos manifestaram-se preocupados "com as nuvens que se adensavam no horizonte" e falavam da exaltação de regionalismos e rivalidades étnicas que faziam perigar a concórdia em Moçambique.

Uma outra explicitava que membros da etnia sena boicotaram a missa na lgreja de São Benedito na cidade da Beira (no centro do país), até que o pároco se decidisse a celebrar o culto nas três línguas admitidas pelo Arcebispado: Português, Sena e Ndau. "Caso não haja consenso, não iremos permitir que o pároco Mucauio continue a trabalhar em São Benedito, e nós passaremos a fazer a celebração da Palavra no lugar da missa. Isto para nós será melhor do que com a presença do padre, que só nos cria confusão", disse um elemento do Conselho Paroquial. Até agora, o 
Ndau intercalava com o Sena. Segundo o jornal, tratava-se de um conflito, que se pretende de âmbito meramente litúrgico, o qual foi desencadeado em 1985 e atingiu a fase mais aguda em 1991, quando D. Jaime Gonçalves, Arcebispo da Beira, proibiu o uso do Sena na celebração da liturgia, proibição essa que não duraria muito tempo.

Por último, uma outra notícia refere a realização de um seminário sobre a padronização das línguas moçambicanas, tendo chegado à conclusão de que as línguas bantos deveriam ser divulgadas através da mídia, com destaque para o rádio. Tais línguas, segundo o jornal, deveriam ser estudadas e padronizadas, pondo em relevo o papel do rádio e da lgreja nesta política de difusão. Em geral, conclui o periódico, a língua portuguesa não é tratada nestes seminários como língua nacional, mas como língua oficial, embora ela seja materna para uma boa parte dos moçambicanos, exclusão que se afigura pouco condizente com a realidade.

É visível que a língua portuguesa como idioma oficial está vinculada à idéia de país, de pátria, de povo. Se existe a necessidade do estudo das línguas moçambicanas, para muitos é, na opinião de Luís Honwana, para ajudar ou facilitar "a língua" e "para nos fazer entender pelas massas" e não porque se considera que "é nelas onde residem, se preservam e se transmitem os principais elementos constitutivos da identidade cultural" (Honwana, 1988, p.3). Essa pertinente observação de Honwana leva-nos a questionar as razões pelas quais estas línguas continuam a manter-se ausentes no processo de letramento da sociedade moçambicana.

\section{Algumas marcas peculiares da cultura acústica moçambicana}

Uma cultura essencialmente oral, como a moçambicana, praticamente não dispõe de textos. Nesta cultura acústica, os seres huma- nos aprendem muito e possuem grande sabedoria, mas não estudam. Como reúnem material organizado para que possa ser recordado? Como se torna possível trazer à memória aquilo que se prepara tão cuidadosamente? A única resposta é: pensar coisas memorizáveis. 0 discurso oral, de um modo geral, tem na repetição uma de suas marcas mais peculiares. É comum atribuir-se o fenômeno à necessidade de reforçar a informação contida numa mensagem que se desenvolve linear e irreversivelmente na cadeia do tempo e que, por esse motivo, não permite qualquer espécie de revisão, quer por parte do emissor, quer por parte do receptor. Há, pois, um retorno constante às palavras-chave ou sentidos-chave, num esforço para evitar a dispersão em relação ao conteúdo fundamental.

Assim, numa cultura oral, para resolver com eficácia o problema de reter e recordar o pensamento cuidadosamente articulado, o processo deverá seguir modelos mnemônicos, formulados para uma rápida repetição oral. 0 pensamento deve originar-se por meio de modelos equilibrados e profundamente rítmicos, em que, entre outros recursos, a repetição desempenha um importante papel. Nessas culturas, os seres humanos aprendem ouvindo, repetindo o que ouvem, decorando provérbios, mas sem estudar no sentido estrito.

No domínio da poesia oral, de um modo geral, e da africana, mais particularmente, a repetição é uma das suas dominantes, concretizando-se em diversos níveis: em nível da palavra, do verso e até de grupos de versos, bem como em nível do sentido, com recurso a palavras diferentes. É, como dissemos, uma característica genérica, que se manifesta na quase totalidade dos gêneros poéticos orais africanos (a poesia panegírica, a poesia elegíaca, a poesia militar e de caça, a poesia lírica, a poesia satírica político-social, a poesia religiosa). 
A poesia do moçambicano José Craveirinha apresenta inúmeros exemplos da concretização do princípio da repetição, inspirados nas formas desta poesia oral (Matusse, 1993, p.105). ${ }^{5}$ Observemos um extrato do poema "Quero ser tambor":

Nem rio correndo para o mar do desespero.

Nem zagaia temperada no lume vivo do desespero.

Nem mesmo poesia forjada na dor rubra do desespero.

[...]

Só tambor velho de gritar na lua cheia da minha terra.

Só tambor de pele curtida ao sol da minha terra.

Só tambor cavado nos troncos duros da minha terra! (Craveirinha, 1982, p.123)

A poesia oral moçambicana, que é cantada ou declamada, é geralmente antifônica, ou seja, existe uma espécie de resposta de um coro ao solista, sendo dessa alternância que a sua performance depende. A repetição integral de um ou mais versos pode corresponder à resposta do coro ao mote dado pelo solista, e o mesmo acontece com o refrão.

Uma outra forma de poesia oral é o provérbio. Segundo Holman e Harmon, o provérbio é "Uma oração ou frase curta e 'memorizável', que expressa algo reconhecido como verdadeiro ou que envolve observações acerca de aspectos práticos da vida" (Holman; Harnon, 1986, p.401). A compressão e concisão que caracterizam o provérbio dependem, em grande medida, do conjunto de recursos estilísticos de que se serve (metáforas, comparações, hipérboles...), o que os torna, quanto à forma, diferentes do discurso ordinário. Essa componente estilística faz do provérbio uma forma muito importante para a literatura oral ${ }^{6}$ africana, pois o seu modelo e as suas técnicas são muitas vezes aproveitados em formas mais elaboradas e mais extensas, como a canção e o conto. É importante notar que os provérbios fazem freqüentemente alusão a fenômenos naturais e à vida animal, o que pensamos, prende-se ao fato de nesses domínios imperar uma espécie de "perfeição", uma lógica imanente e funcional, diferente dos comportamentos humanas, mais instáveis e arbitrários. Em "Terra Sonâmbula", numa seqüência de frases, o escritor moçambicano Mia Couto procura, de forma sintética, caracterizar e justificar, com base numa pretensa verdade universal, a tentação da personagem de abandonar o seu projeto inicial, num dado ponto da ação: “As idéias, todos sabemos, não nascem na cabeça das pessoas. Começam num qualquer lado, são fumos soltos, tresvairados, rodando à procura de uma devida mente" (Couto, 1992, p.44). A narrativa de Mia Couto explora largamente o modelo e a técnica do provérbio nas passagens de caráter reflexivo, sendo este um dos seus elementos marcantes.

Os provérbios não se empregam apenas para armazenar conhecimentos, mas também para comprometer os outros no combate verbal e intelectual: um provérbio desafia os ouvintes a superá-lo com outro mais oportuno ou contraditório. 0 seu caráter moralista é um dos aspectos importantes que, com

5. No entender de Gilberto Matusse, " 0 substrato cultural banto de Craveirinha é ronga, etnia do sul de Moçambique (Maputo e arredores). Isto leva a crer que a inspiração mais direta vem da poesia ronga. Há, contudo, muitas afinidades das formas da poesia ronga com as das poesias de outros povos, mais ou menos próximos geográfica e linguisticamente (os changanas, os chopes, os suazis, os zulus e outros)"(Matusse, 1993, p.105).

6. Walter Ong considera monstruoso o uso do conceito "literatura oral", chegando a afirmar que considerar tradição oral como literatura oral é o mesmo que considerar cavalos como automóveis sem rodas. Em vez da expressão "literatura oral", ele sugere a expressão "formas artísticas exclusivamente orais" ou "formas artísticas verbais" (ONG, 1993, p.20-23). Somos de opinião que Ong, ao fazer este tipo de crítica, se revela demasiado preso à raiz das palavras. Por isso, não vemos razão para não adotarmos a expressão "literatura oral". 
freqüência, incorporam os provérbios. ${ }^{7}$ Eles costumam, também, ser aplicados na jurisprudência. Na opinião de Ong, os provérbios não são meros adornos da jurisprudência, mas constituem, eles mesmos, a própria lei. “Com freqüência recorre-se a um juiz de uma cultura oral para que repita provérbios pertinentes a partir dos quais pode deduzir decisões justas para os casos de litígio formal que lhe são submetidos” (ONG, 1993, p.42).

Um outro aspecto importante a considerar é o de que na realidade cultural moçambicana, assim como nas sociedades ágrafas em geral, constata-se que é principalmente pelo ato de narrar que é possível manter um elo entre os velhos e os novos, e perpetuar a transmissão das vivências e dos conhecimentos antigos.

A narração recorre à fórmula, instrumento privilegiado das culturas acústicas, nas quais a natureza auditiva e mental das palavras está relacionada não só aos modos de expressão e produção cultural, mas aos processos de transmissão e aprendizagem. 0 que se pode relembrar depende de formas mnemônicas, nas quais o ritmo contribui para a lembrança e toda a experiência é intelectualizada mnemonicamente (Goody, 1977, p.112-128). 0 conceito de fórmula a que nos estamos referindo configura uma seqüência de elementos, um esquema organizador, característico às formas orais e sobreviventes nas culturas escritas. A fórmula é aqui entendida, sobretudo, como um procedimento mnemotécnico, um quadro estrutural, um meio de ligar elementos que, sem o apoio da escrita, seriam mais dificilmente memorizados para sua transmissão e difusão. Foi a fórmula, historicamente, um instrumento de construção e transmissão de obras verbais, apoio à memória social e histórica dos povos sem escrita (Goody, apud Le Goff, 1984, p.12).

No entanto, a memória acumulada e transmitida nas sociedades sem escrita, com apoio da fórmula, não era uma memória "pala- vra a palavra", uma rememorização exata. Nessas sociedades, a memória social parece estar mais baseada numa reconstrução criativa do que na memória mecânica.

Adélia Bezerra de Meneses afirma que "não podemos esquecer da carga corporal que a palavra falada carrega. Na narrativa oral, a palavra é corpo: modulada pela voz humana, e, portanto, carregada de marcas corporais; carregada de valores significantes" (Meneses, 1989), dentre os quais se destaca o triunfalismo. Segundo Ong, as culturas orais estimulam o triunfalismo, que, na atualidade, tem tendência a desaparecer, à medida que as sociedades que alguma vez foram orais se voltam cada vez mais para a palavra escrita (ONG, 1993). Tal triunfalismo deixou suas marcas bem vincadas no discurso político das lideranças moçambicanas que, embora já estivessem incorporadas ao universo letrado, no fundo, refletiam, de algum modo, esse passado recente ainda muito vinculado à tradição oral. Assim, não era surpreendente a utilização de palavras de ordem, em que imperava, soberana, a marca do triunfalismo. A título de exemplo, na elaboração pelo Partido e Estado moçambicano do plano de desenvolvimento para a década, emergiu a palavra de ordem “1980-1990:

7. 0 autor, na época em que foi Diretor Provincial de Educação e Cultura na Província de Maputo (1979-1983), trabalhou no Governo Provincial sob a liderança do Governador da Província, General José Moiane, destacado comandante guerrilheiro durante a luta armada de libertação nacional contra o colonialismo português. Este líder dispunha de um verdadeiro arsenal de provérbios que usava com freqüência nas próprias reuniões do Governo Provincial. Numa dessas reuniões, na qual se discutiam as formas de atuação dos membros do governo nos vários distritos que compunham a província já então assolada pela guerra de agressão do regime do apartheid, recordo-me de um Diretor Provincial ter feito uma intervenção na qual procurava sensibilizar o governador para os riscos de atuação dos membros do governo em zonas de guerra. Para o governador, tal membro do governo estava colocando dificuldades para a realização de uma tarefa, mesmo antes de conhecer e visitar o local que Ihe tinha sido cometido. Sua intervenção, feita num tom de grande calma, veio sob a forma de provérbio: "Senhor Diretor, não devemos dizer que aquele saco é pesado, sem que primeiro 0 coloquemos às costas!". 
década da vitória sobre o subdesenvolvimento"; ou quando, perante a ameaça de invasão do exército sul-africano, o presidente Samora Machel discursava num comício e afirmava peremptório (cito de memória): "Que venham! Que venham! Cada palmo de terra será uma tumba para o invasor".

\section{A língua como patrimônio cultural}

A língua escrita e falada de um povo é, possivelmente, seu mais importante atributo cultural. A política colonial portuguesa, na condição de instrumento de um grupo mais poderoso, foi utilizada sistematicamente para dominar o povo moçambicano. A política lingüística, da mesma forma que outras políticas, foi usada como instrumento de dominação, fragmentação e reintegração, dentro de uma estrutura política dominante. Assim, utilizando a língua portuguesa como instrumento de dominação, não é de surpreender que as línguas moçambicanas tivessem sido ignoradas, quando não hostilizadas, pela ordem colonial.

Com a independência de Moçambique ocorrida em 1975, o novo poder político vai utilizar a língua portuguesa como língua de unidade nacional, procurando fazer dela não um "instrumento de dominação, mas, ao contrário, um instrumento de libertação". Se é pacífico aceitar como correta esta estratégia, dado que nenhuma das línguas moçambicanas tem uma cobertura territorial tão avassaladora que pudesse instituir-se como língua nacional, já nos parece, contudo, bastante controversa, ou no mínimo problemática, a política lingüística que foi adotada ante as línguas moçambicanas. Com o falacioso argumento da falta de quadros e da incipiente codificação das línguas moçambicanas, o poder político acabou, por outras vias, dando continuidade à política lingüística colonial. Ou seja, não só as línguas moçambicanas foram igualmente ignoradas, quando não hostilizadas, em nome da coesão nacional que era preciso criar e desenvolver, como também poucos, ou nenhum, esforços foram feitos para preservar e desenvolver as riquíssimas potencialidades da tradição oral, encarada esta, por um lado, como suporte de toda a memória de um povo que era preciso ser resgatada, e, por outro lado, como sustentáculo importante ao aprendizado da língua portuguesa.

Não deixa de ser preocupante que, em Moçambique, inúmeras pessoas, incluindo professores que vivenciaram a época colonial, dificilmente consideram como um problema a política lingüística seguida pelo país após a independência. Elas sustentam com toda a segurança que todos os alunos são perfeitamente capazes de aprender o português, se ele for ensinado de forma adequada. Pensam que tudo o que se diz das línguas maternas tem uma função apenas no desenvolvimento das respectivas culturas, mas deve superar-se a questão da língua de ensino, que somente pode e deve ser em português. Para elas, a necessidade de aprender português é absolutamente urgente e incompativel com todas estas discussões secundárias. É difícil convencê-las de que outra perspectiva pode ser mais eficaz, pois suas próprias experiências de vida parecem provar o contrário.

0 problema é que esta perspectiva pressupõe um contexto de dominação colonial que conseguiu um certo êxito com uma minoria que não tinha outra saída senão sacrificar sua identidade. Este contexto simplesmente não existe mais e não pode ser restaurado por decreto. Tecnicamente, funcionou, sem dúvida, porque não estava obrigado a assumir a reprodução de uma sociedade e de uma cultura plural: poderia simplesmente explorá-la no singular, quer dizer, em português.

Some-se a isto a questão da etnicidade, configurada em Moçambique pela existência de mais de vinte etnias, com as suas línguas e culturas, para se ter um quadro da 
importância que essa problemática tem na atualidade, forte e crescentemente marcada por conflitos reais (muitos deles tendo degenerado em verdadeiras limpezas étnicas) ou latentes. Em Moçambique, não devemos esquecer que a guerra civil, que após a independência fustigou os moçambicanos durante mais de uma década, foi fortemente marcada pela etnicidade. Se hoje tais conflitos parecem estar sob um relativo controle, avolumam-se indícios de que essas tensões étnicas poderão deixar sua latência, explodindo de forma mais violenta e incontrolável quando e onde menos se espera. Se, em vários domínios, não forem levadas à prática políticas que objetivamente garantam o reconhecimento à diversidade cultural existente no tecido social moçambicano, estarão criadas as condições para a eclosão de tais conflitos. Uma dessas políticas é precisamente a política lingüistica, que, ao mesmo tempo que institui a língua portuguesa como língua oficial, deve lançar mão de todos os meios para estudar, pesquisar e desenvolver a riqueza e a diversidade lingüísticas presentes em Moçambique.

As pressões mundiais em favor da assimilação têm um efeito drástico sobre as línguas. Existem, hoje, no mundo, entre 5 e 20 mil idiomas, cada um dos quais reflete uma visão singular do mundo, um padrão de pensamento e de cultura. Porém, muitas dessas línguas encontram-se em perigo de extinção em um futuro próximo, seja pela falta de crianças que as utilizem, seja pelo seu abandono em favor de idiomas metropolitanos, cujos locutores são culturalmente agressivos e economicamente poderosos. Muitas línguas já estão moribundas, e alguns especialistas sugerem que talvez 90\% dos idiomas hoje falados estariam extintos no próximo século (Wurm, 1995).

Essa perspectiva representa uma delapidação de recursos tanto quanto a extinção de espécies animais ou vegetais. Cada língua falada no mundo constitui uma forma singular de considerar a experiência humana e o próprio mundo. ${ }^{8}$ Muitos idiomas desapareceram no curso da história humana. Eles não podem ser mantidos vivos artificialmente por decreto governamental ou por interesses folclóricos, mas tão-somente como resultado da escolha consciente de seus locutores.

Todas as línguas são iguais no sentido de que constituem um instrumento de comunicação; toda língua tem o mesmo potencial como língua mundial. A concretização desse potencial depende das oportunidades que são dadas a cada uma delas. Antigamente, acreditava-se que os idiomas eram como criaturas vivas: nasciam, cresciam, declinavam e morriam. Porém esse quadro é falso: as línguas são, plena e simultaneamente, instrumentos e resultantes das sociedades que as empregam ou que as abandonam. 0 destino de toda língua resulta do ambiente social e político, em particular das relações de poder. ${ }^{9}$

A diversidade lingüística é, portanto, um patrimônio precioso da humanidade; o desaparecimento de qualquer idioma implica o empobrecimento da reserva de saber e a perda de instrumentos para a comunicação intra e intercultural. Não estará Moçambique contribuindo para esse empobrecimento e, quiçá, mesmo para o desaparecimento de seus idiomas? Estará sendo devidamente compreendido o perigo que representa o empobrecimento

8. Se precisássemos ser lembrados dessa realidade, bastaria recordar a riqueza da linguagem yaghan da Terra do Fogo (que, segundo Darwin, "mal merece ser qualificada de articulada"). "0s yaghans têm uma forma dramática de expressar cada contração de músculos, cada ação possível da natureza ou do homem" (Chatwin, 1988).

9. Deve-se acrescentar aqui uma referência às vantagens observadas nas pessoas bilíngües ou multilíngües, mais habituadas às mudanças de padrões de pensamento, sendo, portanto, mentalmente mais flexíveis. A familiaridade com conceitos diferentes ou contraditórios torna essas pessoas mais tolerantes do que as monoglotas, e mais capazes de compreender os vários aspectos e um problema. Os lingüistas salientam, portanto, a urgência de elaborar descrições e gramáticas, léxicos, textos e registros antes da extinção de idiomas. 
do pensamento moçambicano resultante da extinção de idiomas? ${ }^{10}$

\section{Letramento: reforço ou silenciamento da memória coletiva?}

Um dos problemas da história da memória é a discrepância entre o que a história feita pelos historiadores (a história erudita) possa dizer de um acontecimento passado e as percepções que prevaleçam, no mesmo momento, no seio de uma sociedade, num tempo e num local determinados, e que, certamente, têm um peso infinitamente maior. A história da memória é um excelente exercício crítico e permanente a realizar pela história erudita como forma de evitar a ilusão nefasta que consiste em acreditar que os historiadores são os depositários da verdade histórica. A história, nunca é demais lembrá-lo, pertence, sobretudo, àqueles que a viveram e é um patrimônio comum que cabe ao historiador exumar e tornar intelegivel a seus contemporâneos.

Se é pacífico aceitar a memória como um elemento essencial da identidade, da percepção de si e dos outros, essa percepção difere segundo nos situemos na escala do indivíduo ou na escala de um grupo social, ou mesmo de toda uma nação. Se o caráter coletivo de toda memória individual nos parece evidente, o mesmo não se pode dizer da idéia de que existe uma memória coletiva, isto é, uma presença e, portanto, uma representação do passado que seja compartilhada nos mesmos termos por toda uma coletividade.

Não se deve ignorar a tensão freqüente entre as memórias locais e a retórica nacionalista pública, uma tensão que se intensifica quando a comunidade imaginada nacional torna-se muito circunscrita. As comunidades locais, por exemplo, podem-se apropriar de formas materiais de comemoração nacional, como monumentos à guerra, mas não necessariamente de seu conteúdo, submetendo a ex- pressão da memória aos interesses locais.

A escola, que nasceu colada à reprodução da cultura, do saber, dos hábitos e comportamentos, ligada aos processos mais imediatos e totais da socialização, não consegue divorciar-se da tradição - biologicamente, tão indispensável à espécie humana e tão necessária à sobrevivência e identidade do grupo. Todas as tentativas de converter a experiência escolar num exercício de apreensão lógica, metódica de habilidades e saberes ante o futuro - apreender para a vida, o trabalho, a cidadania -, não conseguiram desvincular a escola dessa função de cultivar a memória do passado.

A escola está intimamente associada à construção de identidades: tematizar e explorar os espaços, os objetos, as lembranças corpóreas. A pedagogia escolar na educação básica continua fiel às velhas normas: celebrar o passado, encontrar símbolos dos fatos que se deseja recordar e provocar sentimentos para as crianças aderirem a eles com paixão. Das três potencialidades humanas a serem cultivadas por toda a ação pedagógica (memória, intelecto, vontade), apenas o cultivo do intelecto merecerá a atenção quando se ultrapassa a idade infantil, quando a escola deixa de brincar de ensinar e passa a ensinar.

10. Por exemplo, muitas plantas medicinais são conhecidas apenas por pessoas imersas em culturas tradicionais, com linguagens que dão nomes específicos a elas. 0 desaparecimento dessas linguagens e culturas acarreta a perda do conhecimento sobre tais plantas e suas propriedades de cura, a não ser que um lingüista ou outra pessoa interessada tenha gravado seus nomes e uma descrição de suas propriedades, antes da extinção do idioma. As qualidades de cura do curare ou do quinino, por exemplo, são conhecidas dos índios da América do Sul desde muito antes do contato com os europeus. No norte da Austrália, constatou-se, recentemente, que doenças como graves úlceras de pele, incapazes de serem curadas por métodos alopáticos, foram rapidamente tratadas com loções à base de plantas batizadas por membros de grupos aborígines. 0 sucesso desse e de outros tratamentos tradicionais similares inaugurou uma ampla busca por outras plantas medicinais com a ajuda dos povos aborígines por meio das palavras por eles empregadas em suas próprias línguas, que se encontram em vias de extinção. 
Não é apenas na educação do adolescente e do jovem que se perdem as ricas dimensões da evocação do passado. Também na educação básica das crianças, há perdas significantes. As reformas educacionais tendem a impor curriculos cada vez mais rígidos, guiados por uma concepção cada vez mais racionalista da educação escolar. 0 intelecto e o seu cultivo, ou melhor, o adestramento, impõem-se sobre as outras potências do espírito, memória e vontade. Uma corrente pedagógica antimemória infiltra-se em nome da centralidade do intelecto. Centralidade posta por uma concepção racional: a formação do sujeito racional, de sua autodeterminação racional, da compreensão teórica do real etc.

À memória do passado contrapõe-se o conhecimento lógico - antecedentes, determinantes, conseqüências, a busca das causas, das últimas causas. Esse conhecimento se legitima como o mais perfeito, o único conhecimento, enquanto a memória é relegada à esfera do impreciso, ao mágico, ao imaginário. Daí ser tolerada, apenas, na primeira infância, no tratamento que a escola dá à recordação do passado; à medida que a criança se aproxima da idade da razão, esse tratamento do tempo passado deverá ser descartado. Entre a $4^{\text {a }}$ e $5^{\text {a }}$ séries (e, por vezes, antes), dá-se esse corte, como é fácil de constatar nos livros didáticos e na própria organização do tempo e do trabalho pedagógico. 0 conhecimento passa a ser metódico, com lógica, sem emoção e paixão, sem evocação. Contrapõe-se a inteligência à memória nos programas escolares, enquanto os psicólogos, como Jean Piaget, demonstram que memória e inteligência, longe de se contrapor, se apóiam mutuamente. E são vínculos primários da codificação e reprodução das relações sociais.

É curioso constatar que, ao mesmo tempo que os tempos passados, a memória coletiva sofre uma verdadeira revolução documental nos bancos de dados, no computador, torna-se memória eletrônica; ao mesmo tempo a memória do passado se expande na literatura, na filo- sofia e na psicologia, destacando dimensões da memória pessoal, do espírito, das emoções e sonhos (do subconsciente). Essa memória não é tratada como um vasto reservatório, ao estilo da memória eletrônica. Nem se situa no nível do consciente, do dado concreto. Está mais próxima do latente, construído, principalmente, na infância.

Na última década, falou-se muito dos vínculos entre saber e poder, entre o domínio das habilidades e dos saberes no confronto entre dominantes e dominados. As análises do currículo escolar acentuaram essas dimensões políticas. Entretanto, o discurso ficou reduzido ao chamado saber acumulado e a sua transmissão disciplinada nas séries e disciplinas escolares, nos livros didáticos e na docência dos mestres competentes. Numa visão reducionista, reivindicou-se que a escola ensinasse, chegando a condenar-se as festas e comemorações como tempo perdido - que desvirtuava essa função docente-transmissora e ocupava tempos, escassos, na alienação dos futuros cidadãos conscientes. A escola, em seu tradicionalismo, não abandonou o que a constituiu em suas origens mais remotas: cultivar a consciência, o sentimento do passado, da tradição histórica. Comemorá-los, cantá-los, evocá-los, porque a consciência e o sentimento do passado não é outra coisa senão a consciência do grupo, de cada indivíduo, de sua identidade cultural.

A escola não conseguira fugir a esse papel, que traz como marca de origem, como expressão digital. Poderá sim, recuperá-lo, abrir maiores espaços no cultivo do passado público e privado, tratá-lo com maior competência e, sobretudo, democratizá-lo para que minorias não monopolizem a memória social e com elas destruam as identidades ou as enfraqueçam. Não será uma minoria (no caso moçambicano, sulista), que, desde os tempos da luta armada contra o colonialismo português e no pós-independência, ocupou altos cargos na cúpula dirigente da Frelimo, que tem monopolizado 
essa memória social do povo moçambicano? Será possivel pretender captar a história de uma memória nacional unicamente pelo viés de grupos restritos ou de setores da sociedade particularmente sensibilizados pelo passado ou que têm tendência, como o Estado, a propor representações do passado? Que representações dele fazem os grupos mais amplos e mais heterogêneos? Na sociedade moçambicana, de forte tradição oral, os especialistas da memória são os velhos. São eles a memória da sociedade. Sua importância é de tal natureza que quando um velho morre se costuma dizer que "uma biblioteca desapareceu". Na luta pela dominação da recordação e da tradição histórica, a escola pode cumprir um papel relevante, não abandonando, antes retomando, o peso político e cultural do cultivo da memória do passado tanto coletivo quanto individual. A escola não pode abandonar a força do simbólico, a força da imagem. Todos os nossos sentidos podem despertar lembranças e emoções e é a escola, nas suas origens, uma das instituições mais visíveis de evocação do passado. Mas um passado não institucionalizado, cuja incorporação na escola possa representar a democratização da memória e a possibilidade de novos espaços de defesa de identidades tidas como marginais: identidades populares, de classe, gênero, etnia.

A escola é determinante na produção das lembranças e no processo de recordação. Se dependesse da experiência e tradição escolar, seria difícil cairmos no esquecimento do passado. Todas as culturas têm um conjunto de processos diferenciados de educação da memória. Nas sociedades modernas, a escola destaca-se por seu caráter técnico, ritual, institucionalizado de educar a memória coletiva mais do que as memórias individuais. 0 aluno não encontra espaço para que eduque a sua memória étnica, de classe ou de gênero. Na verdade, o que a escola cultiva não será uma memória coletiva seletiva? Sendo seletiva, não será difícil à escola fugir ao processo de manipulação consciente ou inconsciente que o poder e uns grupos sociais exercem sobre a memória individual, grupal, étnica e de classe? Terá o letramento participado no cultivo da memória coletiva e também nos esquecimentos e nos silêncios de vestígios históricos reveladores de identidades e de lutas?

0 passado não garante o presente e menos o futuro, ao contrário, é mais fácil que o presente e o futuro redefinam o passado e, freqüentemente, o destruam. 0 tempo corta e alarga muitos sonhos. As pedras e as marcas num determinado espaço podem permanecer, mas outros tempos e vivências redefinirão seus sentidos. A escola tende a não trabalhar com o presente, nem mesmo com o futuro. Mas os caminhos da memória só têm sentido se abrirem as trilhas do futuro.

\section{Letramento, poder e contexto sócio-cultural}

A implantação de um sistema escolar ocidental em ambientes de culturas acústicas cria uma situação na qual essas culturas, só pelo fato de não possuírem alfabeto, acabam sendo designadas como inferiores. Além disso, se o sistema escolar utiliza uma língua estranha ao ambiente social, esta situação se agrava. A possibilidade de que alguns sábios nativos realcem a passagem da oralidade à escrita é teles(copiada) pela introdução de outra língua para o escrito, representando, também, não somente uma técnica de escrita, mas também todos os diferentes conteúdos e conceitos que uma cultura letrada elabora com a própria força da escrita, e que, neste caso, é, além do mais, uma cultura estrangeira. Deste modo, a língua de oralidade fica posta numa situação de debilidade ante as tarefas ligadas às novas condições, de duas maneiras: falta o desenvolvimento produzido pela escrita, e falta a continuidade como cultura própria neste processo.

Devido, sobretudo, aos efeitos da guerra que ocorreu em Moçambique durante cerca 
de uma década e meia no pós-independência, registraram-se migrações em massa do campo para a cidade. Numa escala jamais vista no país, este fenômeno inseriu populações deslocadas e dispersas e suas culturas de origem num complexo processo de interação. Neste processo, uma das questões mais delicadas é a que diz respeito à língua. Na verdade, a própria natureza da linguagem resume toda a questão do pluralismo - cada uma das línguas mais faladas representa um modo único de conceber a experiência humana e o próprio mundo. Como toda política, a política lingüística moçambicana, contudo, estará ainda no pós-independência, a ser utilizada como instrumento de dominação, de fragmentação e de assimilação?

No contexto moçambicano, parece-nos ser de fundamental importância uma política lingüística esclarecida em relação à preservação das línguas faladas pelas diversas etnias, ao mesmo tempo que se possa oferecer a elas a oportunidade de ingressarem em uma comunidade mais ampla. Assim, o setor educacional vê-se diante de vários desafios. Estarão as escolas moçambicanas progressivamente a se organizar para ensinar várias línguas maternas, ao mesmo tempo que a língua portuguesa - definida pelo poder político como língua de unidade nacional -, de maneira a oferecer às pessoas a possibilidade de proceder a escolhas que fortaleçam suas capacidades individuais? Isso eqüivaleria a elaborar uma forma de educação verdadeiramente intercultural, isto é, que oferecesse às diversas culturas étnicas um lugar melhor não apenas no sistema educacional, mas também na imagem da cultura nacional que o país procura adotar e proteger. Essa tese estará ainda encontrando resistência na política governamental, que ainda vê a proposta como uma ameaça à integração nacional?

$\mathrm{Na}$ multicultural sociedade moçambicana, a redução dos conflitos internos sociais e culturais depende, a longo prazo, da expansão da base econômica, do crescimento do emprego e da elevação dos níveis de vida. Também é verdade que o processo de desenvolvimento econômico puro e simples pode criar ou exacerbar os conflitos culturais e sociais. Os planos de modernização, que envolveram programas ambiciosos de alfabetização e de educação do pós-independência, produziram um grande número de jovens instruídos ou semi-instruídos, muitas vezes sem emprego ou sem a ocupação desejada. As expectativas cresceram mais rápido do que as possibilidades econômicas, e isso constitui um terreno fértil para o descontentamento e a revolta contra certos grupos. A juventude desempregada dos centros urbanos tem sido o participante mais visível e ativo nos movimentos de contestação social e, em Moçambique, à semelhança do que ocorre em outras regiões do planeta, ela terá tendência a se envolver em possiveis, e porque não previsíveis, convulsões etnonacionalistas. Sabe-se que os conflitos resultantes do contato entre diferentes populações em outros pontos do globo têm contribuído para reforçar as identidade étnicas, particularmente quando o processo de migração gera a competição pelo acesso à riqueza econômica, ao poder político e ao status social. lsso também ocorre quando existe uma forte noção de etnicidade territorial, na qual certos grupos étnicos se consideram enraizados no espaço físico como "filhos da terra”, ou quando a migração gera bruscas mudanças no equilíbrio demográfico e na mistura entre grupos étnicos, principalmente nas grandes cidades. No caso moçambicano, uma grande parte dos migrantes provenientes de regiões rurais, com sua línguas e costumes, são freqüentemente seduzidos pelas melhores perspectivas de vida nas grandes cidades, aceitam empregos sem qualificação e de baixo nível. A sua sorte se deteriora, automaticamente, quando as condições econômicas pioram e quando a população local deseja expulsá-los. Uma outra situação pode também ocorrer quando determinados estratos da população (por exemplo, os moçambicanos de 
origem européia, a comunidade de origem indiana) na maioria dos casos têm qualificações superiores às da população local, e desfrutam de afluência e prestígio social. Esse contexto pode conduzir a uma situação particularmente amarga e conflituosa, em especial no período imediatamente posterior à colonização e à independência, quando a população moçambicana, anteriormente em posição desvantajosa, ao lograr produzir uma juventude instruída e qualificada que aspira a assumir profissões e empresas anteriormente gerenciadas ou possuidas pelos colonialistas, procura se substituir a eles. Mais recentemente, a vontade de afastar pessoas que ocupam posições importantes nos setores modernos torna-se particularmente aguda, quando o nível do emprego naqueles setores não se expande de maneira suficientemente rápida para incorporar à classe média a população local emergente.

\section{Limites e possibilidades dos programas de ensino em língua materna}

Um programa de língua materna como língua de ensino não é necessariamente o melhor programa, se o objetivo é alcançar uma forma de bilingüismo, isto é, se também queremos promover a aprendizagem de uma segunda língua; e se queremos alcançar um elevado grau de êxito nos resultados escolares em geral. Além disso, é equivocado pretender que o ensino com a língua materna como língua de ensino é sempre a melhor a solução. Em nosso entender, tudo dependerá da organização total do programa.
Gustavo Callewaert (s./d., p.8) procura mostrar, por meio de um esquema, as várias modalidades de programas que combinam a língua materna com a língua segunda (ver tabela abaixo).

Um exemplo de um programa de segregação é o que ocorreu nas escolas segregadas para alunos Ovambo, na Namíbia, antes da independência. Na escola primária, ensinavam-se os alunos em oshivambo, com um ensino mínimo da segunda língua (a língua oficial desta época, afrikaans, na maioria dos casos). Todo o programa era um programa reduzido, que resultava um baixo grau de conhecimento de ambas as línguas, e maus resultados escolares (Callewaert, s./d., p.12).

Existe um elevado número de casos de programas de submersão nos países africanos, nos quais a antiga língua colonial é a língua de ensino, com maus resultados em toda a parte. É o caso de Moçambique, Zâmbia, Guiné-Bissau, entre outros.

Por outro lado, há um número significativo de países africanos que adotaram um sistema de transição: durante os primeiros anos, ensinam-se os alunos na sua língua materna, para que se adaptem à escola e à cultura escolar, a partir da sua própria língua e cultura. Ás vezes, a segunda língua também se ensina como disciplina de forma progressiva. Se isso não é feito, e se o sistema funciona apenas durante poucos anos, estes alunos não são, na realidade, alfabetizados na língua materna. Se, além disso, a língua materna não for ensinada como disciplina durante toda a escolarização, o programa de transição não contribui para o desenvolvimento da língua

\begin{tabular}{||l|c|c|c|c||}
\hline \multicolumn{5}{|c|}{ ESQUEMA DE PROGRAMAS QUE COMBINAM LÍNGUA MATERNA E LíNGUA SEGUNDA } \\
\hline Nome do programa & Segregação & Manutenção & Submersão & Imersão \\
\hline Língua de ensino dominante & \multicolumn{2}{|c|}{$1^{\mathrm{a}}$ Língua (materna) } & \multicolumn{2}{c||}{$2^{\mathrm{a}}$ Língua } \\
\hline Objetivo do ensino & Dominar $1^{\mathrm{a}} \mathrm{L}$ & Bilingüismo & Elite que domina $2^{\mathrm{a}} \mathrm{L}$ & Bilingüismo \\
\hline Objetivo social & Apartheid & Integração & Perpetuar classes sociais & Enriquecimento \\
\hline
\end{tabular}


materna, funcionando apenas como trampolim para a segunda língua e cultura.

Os programas de transição devem considerar-se como programas de submersão, na medida em que o ensino na língua materna não se desenvolve até a um nível de letramento completo, mas unicamente durante um certo tempo e na medida necessária para se poder dar início ao ensino da segunda língua.

Os programas do Canadá são exemplos de programas de imersão com bons resultados, mesmo com minorias que falam uma língua de pouco prestígio. 0 programa de imersão em inglês para os que têm o chinês e o japonês como língua materna não impede o desenvolvimento de suas línguas maternas, fato que igualmente ocorre por todo o ambiente social. Mas são línguas de cultura letrada de elevado prestígio em seu ambiente de origem. E conservam este prestígio dentro da comunidade (Callewaert, s./d., p.12-13).

0 que produz a diferença em todos os casos de aplicação dos programas de ensino em língua materna é o modo de organizar o ensino, bem como uma lista dos fatores importantes para levar os alunos a entender, ler e escrever, comunicar e pensar nas duas línguas em nível elevado. Naturalmente, a idade, o sexo, a classe social, a capacidade intelectual e o número de anos e permanência num país têm igualmente uma grande influência. Mas a questão é que estes fatores estão fora do controle da escola, não podendo esta eliminar tal impacto. Somente pode evitar que seu próprio programa aumente as diferenças causadas por estes fatores ou crie novas diferenças. Como não é objetivo deste trabalho tratar de questões amplas visando revolucionar a estrutura da sociedade, mas organizar um melhor ensino para todos na sociedade atualmente existente, pensamos que um programa escolar deve concentrar-se nos fatores sobre os quais a escola pode influir. Pensamos, também, que o monolingüismo não é uma solução, dado que isto implicaria, a longo prazo, na destruição da maioria das línguas existentes no mundo. É o que têm feito, por todo o lado, os modernos Estados-nacionais ocidentais, criando a ilusão de que o monolingüismo é o estado natural de um Estado moderno.

Para que os programas de manutenção e de imersão tenham êxito torna-se necessário que, paralelamente, existam programas alternativos, de modo que os alunos possam escolher livremente esses programas, para os quais se sintam motivados.

É igualmente importante que o nível de conhecimento da segunda língua de todos os alunos não seja extremamente diferenciado antes de chegarem à escola. Caso contrário, o ensino aumentará essas diferenças, por estar pouco adaptado ao nível dos alunos de menor conhecimento.

Quanto aos professores, importa que não só tenham uma boa formação, como também sejam bilíngües. No caso de não existirem professores com esses dois requisitos, é mais importante que o professor seja bilíngüe do que tenha uma boa formação.

No que se refere aos materiais, é importante que existam materiais didáticos bilíngües e que os conteúdos do ensino não só estejam sintonizados com a cultura do aluno, mas também possibilitem a abertura a novos elementos de cultura. Não adianta dar prioridade à língua materna se os conteúdos não estiverem articulados com a experiência mental e material do aluno, que esta língua materna, em primeiro lugar, expressa, e, a partir dela, puderem entrar outros conteúdos, ligados a outras experiências.

Em absoluto, nada se consegue se o aluno não tiver confiança e não puder atuar por si mesmo. Por isso, o professor deve ser bilíngüe e permitir ao aluno um período de silêncio e de não-escrita na segunda língua, mesmo que se trate de um programa de imersão. 0 professor e os conteúdos devem demonstrar uma valorização positiva dos valores 
do aluno. Nada se pode fazer se se violenta completamente o aluno, fazendo-o sentir-se inferior e com sentimentos de angústia. Ninguém nega a importância do clima afetivo, mas, muitas vezes, os conteúdos e a língua de ensino provocam o clima negativo que todos querem evitar.

Para aprender uma segunda língua, o aluno deve dominar sua língua materna no mesmo nível de aprendizagem que o nível definido como objetivo para a segunda língua. A primeira é um instrumento para aprender a segunda. 0 tempo utilizado para a língua materna não está perdido, somente aumenta a eficácia de aprendizagem da segunda. Isto implica que o ensino em língua materna e da língua materna deve englobar um conjunto de conceitos, argumentações etc. Não é correto utilizá-la em um nível infantilizado. Isto significa que o aluno deve poder desenvolver sua própria língua materna também no ambiente extra-escolar.

Naturalmente, o ensino da segunda língua deve ter um bom nível, com metodologia de segunda língua, adaptado ao nível geral e lingüístico dos alunos.

Uma das coisas que muitas vezes faltam são as oportunidades de praticar a segunda língua fora da escola, ou de ter contatos com pessoas para quem esta segunda língua é a língua materna. Nos países da Europa, os alunos filhos de imigrantes têm estas possibilidades num grau elevado. Isto explica o fato de muitos alunos com um ensino deficiente na escola aprenderem, sem grandes problemas, a segunda língua, ao contrário das mães que se encontram isoladas em casa.

Por outro lado, deve-se recordar que esta análise parte do pressuposto que a língua primeira ou materna é uma língua de cultura letrada. A análise se complica se se trata de línguas de oralidade. Exige-se, por tal motivo, que as línguas moçambicanas - línguas de oralidade - possam ser quanto antes codificadas.

\section{Educação intercultural}

Cada vez com mais pertinência, parece impor-se uma pedagogia do intercultural, que tenha em conta a diversidade como característica das populações escolares nos dias atuais e se apóie no enriquecimento mútuo dos alunos. Na palavra, o importante, em suma, é o prefixo inter: ele indica, na verdade, que se põe a tônica nas trocas entre os alunos, nas conexões, articulações, comunicações, diálogos, sendo que cada um se pode beneficiar do outro.

Isto distingue o intercultural do multicultural que indica mais um estado das sociedades (todas elas são doravante, em maior ou menor grau, pluriculturais). Multicultural é um termo estático, que pode muito bem, na realidade cotidiana, traduzir-se pela simples justaposição de culturas múltiplas no interior de uma sociedade, sem comunicação entre elas, cada uma permanecendo fechada o máximo possível. 0 intercultural, ao contrário, é movimento e reciprocidade.

Assim, o traço fundamental de uma pedagogia intercultural consiste no seu direcionamento para a alteridade, sua abertura ao outro. 0 outro também, como eu, é um sujeito (ativo, responsável, dotado de um capital cultural próprio). Uma competência intercultural é, neste sentido, sempre diferente de uma simples competência cultural (o que já não é mau) em que ela é especificamente orientada para um vizinho que é considerado, nestas condições, como um parceiro, isto é, alguém com o qual estabeleço trocas de igual para igual, com o qual coopero, com o qual trabalho em conjunto na perspectiva de benefícios mútuos. 0 papel do ensino consiste, então, em organizar, facilitar e, sobretudo, otimizar esta troca acordada.

Para que os jovens provenientes das várias culturas moçambicanas possam se situar no mundo, necessitam compreender a função da cultura em geral. Tendo isso em mente, 
eles devem ser ajudados para que se conscientizem de que nenhuma cultura pode pretender invalidar outra, na medida em que se trata de um processo e, em certo sentido, de uma linguagem ou forma e comunicação. É possível, contudo, que uma cultura seja enriquecida com novos conceitos, novas categorias e novos elementos de reflexão; por isso, consideramos de vital importância a adoção de uma visão holística da cultura na esfera educativa. Se as culturas são tão relativas e numerosas como os idiomas, elas são tão operativas quanto esses idiomas. Elas não corporificam a verdade - sequer a verdade do orador. Ao contrário, referem-se às verdades de forma idiomática $\mathrm{e}$ alusiva, expressando valores e normas comuns a todos.

As mentes jovens não têm problema com a pluralidade lingüística. Em uma pesquisa recente realizada em 104 países, 31 declararam possuir duas línguas oficiais de ensino, e 15 afirmaram possuir três ou mais línguas (UNESCO, 1991). 0 desenvolvimento do plurilingüismo desde cedo nas crianças e nos adolescentes, juntamente com a iniciação em sala de aula ao pluralismo de línguas, culturas e religiões, parece-nos ser uma perspectiva a seguir. Nessa perspectiva, o aprendizado de idiomas não deve limitar-se a simples exercícios lingüísticos; deve proporcionar oportunidades de reflexão sobre outras formas de vida, outras literaturas, outros costumes. 0 ensino de disciplinas, tais como história e geografia, também deveria ser reexaminado, a fim de refletir essa exigência. Em vez de concentrar-se em guerras, conquistadores e heróis, por que não apresentar essas matérias aos alunos mostrando-lhes todos os atores da história, os encontros de tradições culturais e as abordagens interdisciplinares? Esse processo poderia conduzir à co-produção de livros didáticos, com o objetivo de despertar a consciência da herança comum, da coincidência de valores e de uma visão comum de futuro. Programas de intercâmbio para jovens profissionais (viagens de estudo, estágios, cooperação para o desenvolvimento cultural) poderiam igualmente ser multiplicados; profissionais da educação seriam treinados para ensinar e para estabelecer exemplos de sensibilidade intercultural.

Os jovens poderiam ser iniciados na noção de complexidade, nos complexos mecanismos de personalidades e culturas, na multiplicidade das formas e dos meios de expressão, na infinita diversidade de personalidades, temperamentos, aspirações e vocações. Apenas por meio da clara compreensão dessa complexidade é possível que apreendam a noção de relações recíprocas.

A educação deveria, portanto, inculcar um certo sentido de relatividade, de diversidade e de tolerância, enfatizando a singularidade da experiência humana, a variedade de culturas e o longo registro histórico das inter-relações dos grupos humanos. A identidade constitui uma referência para o relacionamento e não uma fortaleza. Reconhecer isso implica uma abertura mútua, um relacionamento que é, por definição, uma via de mão dupla. Crianças de grupos minoritários (bem como seus pais) devem ser ajudadas a compreender que o apego mais profundo à riqueza espiritual herdada do passado não exclui a noção de que essa herança possa chegar a um acordo com alguns dos aspectos mais inéditos e perturbadores do presente. Elas deveriam ser incentivadas a aprender o idioma dominante como o seu próprio, da mesma forma que a maioria deveria ser incentivada a aprender as línguas das minorias.

Importa lembrar que a educação não deveria limitar-se às crianças e aos jovens, mas abranger também os adultos. As campanhas de alfabetização mais eficientes nos países em desenvolvimento são as que tiveram como meta a totalidade das famílias nas zonas rurais: mães, pais e crianças, e, às vezes, os próprios avós, primos, tias e tios. 0 princípio da educação permanente, a oportunidade de os adultos voltarem a aprender em 
qualquer fase de suas vidas, a fim de acompanhar o progresso do conhecimento, deveria constituir um objetivo de todas as sociedades.

\section{Conclusão}

Um dos principais fatores responsáveis pela falta de êxito escolar nos países da periferia, como é o caso de Moçambique, é a falta de um bilingüismo sistemático que utilize um letramento completo até um nível suficientemente elevado na língua materna como base de um letramento numa segunda língua. Uma análise rigorosa de todas as experiências poderá mostrar a importância decisiva dessa base, ainda que só isso não seja suficiente.

Muitas vezes, esta realidade não é reconhecida, porque os especialistas preferem a utilização de línguas francas e segundas para evitar a multiplicação de inversões, considerando o monolingüismo como um fator positivo para a aglutinação das diferentes etnias de um Estado numa Nação, e para a modernização considerada como uma proposta do desenvolvimento econômico. Estes especialistas, que dominam todas as grandes organizações internacionais, reproduzem o método utilizado pelas classes dirigentes dos Estados-nacionais dos países industrializados, que, historicamente, alcançaram a designada civilização pela opressão e eliminação de línguas, culturas e, às vezes, povos. Na realidade, este método, além de ser opressor, revela-se, na atualidade, pouco eficaz. Todas as pesquisas mostram que deste modo estas populações não se unem política e culturalmente, não se desenvolvem economicamente, nem são escolarizadas com êxito. Continuam marginalizadas e continuam provocando um conjunto de problemas que, em última análise, se procuram solucionar com intervenções militares efetivadas por forças nacionais e internacionais. Um povo que tenha segurança, um bom nível de vida, liberdade e identidade, em vez de violência, miséria, repressão e alienação, pode constituir-se como
Estado nacional e com identidade nacional, independentemente do fato de o Estado ser mono ou multilíngüe, mono ou multicultural etc. Há muito, sabe-se que o desenvolvimento econômico não significa o mesmo que modernização. Contudo, os Estados industrializados, que são apontados como exemplo, não solucionaram os problemas resultantes da criação de minorias sociais, culturais e lingüísticas e marginalizadas, hoje como antes. Será possível que um dia, as elites dos países industrializados e menos industrializados, senão por respeito aos direitos, pelo menos por uma decisão de conservação de si mesmas, escolham outro caminho?

A situação lingüística que descrevemos, embora criada pela violência da colonização, prosseguiu pelo novo Estado surgido da independência. Para nós, que somos herdeiros desta situação, a única solução justa e efetiva parece ser a promoção de um bilingüismo ou multilingüismo oral e escrito. Isto implica a transformação da língua de oralidade em língua escrita e a conservação de uma língua estrangeira como segunda língua. Esta segunda língua, sendo língua oficial, terá um papel importante em muitas áreas sociais, como a comunicação oficial do Estado, os contatos internacionais etc.

Mas essa transformação não depende somente do trabalho dos técnicos e da existência de meios de comunicação. Depende, também, da evolução destas culturas acústicas. Nesse sentido, podemos dizer que a causa principal da situação de debilidade em que se encontram essas línguas resulta da falta de um desenvolvimento econômico e social como conseqüência não só da colonização, mas também dos erros da política de Estado e da cooperação internacional. Se estas sociedades continuarem reproduzindo-se principalmente sobre a base de sua estrutura tradicional e, além disso, com uma estagnação ou até mesmo uma regressão, não haverá necessidade nem meios para se transformarem em culturas 
letradas. Sem dúvida, estes povos já estabeleceram um contacto útil com a cultura letrada, de modo que a oferta de um sistema escolar poderá ser adequada, se a escola, em vez de oferecer um modernismo abrupto sem continuidade com a tradição, for o local onde se organizaria a passagem entre estes dois tipos de cultura, o que pode constituir a base para uma valorização da língua local, juntamente com o aprendizado de uma segunda língua.

As diferenças, particularmente as lingüísticas, não podem ser vistas como uma penalização, mas podem, ao contrário, tornar-se um enriquecimento mútuo desde que se trabalhe com elas em vez de tentar erradicá-las. Todas as sociedades serão, doravante, multiculturais e, portanto, plurilíngüísticas. Todas as culturas deverão ser iguais em dignidade, e, em decorrência desse fato, pedagogicamente, a opção potencialmente mais rica é aquela da fertilização recíproca. As oposições e resistências a esta perspectiva sempre foram numerosas e fortes (por vezes, brutais) ao longo do tempo.

$\mathrm{Na}$ medida em que se privilegia a diversi- dade e a alteridade, o intercultural situa-se explicitamente na universalidade. Estrangeiro e indígena não são noções intrínsecas, mas relativas uma à outra. Neste quadro, o conceito universal-singular, elaborado pela filosofia alemã do século XIX, está presente em todos os lugares (universal) e que cada cultura (nacional, regional, local, patrimonial) interpreta à sua maneira (isto é, de modo singular), distinta de todas as outras e possuindo modalidades específicas.

A luta pelo intercultural, se, por vezes, me parece ganha pedagogicamente, não se torna visível no seio da sociedade global. A xenofobia e o racismo não regrediram, longe disso, e os fechamentos tendem novamente a se sobrepor às aberturas. 0 etnocentrismo, que o intercultural se propõe erradicar, conserva uma força considerável e, talvez, crescente. Mas, como se sabe, o trabalho educativo exige uma longa paciência e a evolução é lenta. Ela é, entretanto, perceptível, e, no conjunto, o intercultural traça seu caminho para uma intercompreensão entre os homens.

\section{Referências bibliográficas}

CALLEWAERT, Gustavo. Algunas definiciones de programas de lengua de enseñanza en situaciones de multilinguismo. Programa Postgraduação Bissau-Copenhague (PEP), (s./d.), 16 p. [mimeografado]

CHATWIN, Bruce. In: Patagonia. London: Pinguin Books, 1988.

COUTO, Mia. Terra Sonâmbula. Lisboa: Editorial Caminho, 1992.

CRAVEIRINHA, José. Karingana ua Karingana. Lisboa: Edições 70, 1982.

FRAGO, Antonio Viñao. Alfabetização na sociedade e na história: vozes, palavras e textos. Porto Alegre: Artes Médicas, 1993.

G00DY, Jacques. La raison graphique: la domestication de la pensée sauvage. Paris: Les Editions de Minuit, 1977.

HAVELOCK, Eric. A revolução da escrita na Grécia e suas conseqüências culturais. São Paulo: UNESP; Rio de Janeiro: Paz e Terra, 1996.

HOLMAN, C. Hugh; HARMON, William. A handbook to literature. $5^{\text {a }}$ ed. New York: Macmillan, 1986.

HONWANA, Luís Bernardo. Encorajar uso social das línguas moçambicanas. Notícias, Maputo, 1988.

LE GOFF, Jacques. "Memória": história. In: ENCICLOPÉDIA Einaudi, 1984, v.1, p.11-50. 
MATUSSE, Gilberto. A construção da imagem de moçambicanidade em José Craveirinha, Mia Couto e Ungulani Ba Ka Khosa. Lisboa, 1993. Dissertação (Mestrado) - Faculdade de Ciências Sociais e Humanas da Universidade Nova de Lisboa. [mimeografado].

MENESES, Adélia Bezerra de. Do poder da palavra. Folha de São Paulo, São Paulo, 29 jan. 1989.

ONG, Walter. Oralidad y escritura: tecnologias de la palavra. Buenos Aires: Fondo de Cultura Económica de Argentina, 1993.

SOARES, Magda Becker. Letramento/Alfabetismo. Presença Pedagógica, Belo Horizonte, n.10, 1996.

UNESCO. Special survey on primary education, II: languages of instruction and establishment of the curriculum. Divisão de Estatísticas da Unesco, 1991.

WURM, S. A. Endangered languages of the world. 1995.

WUS (World University Service-UK)/ INDE. Educação em Moçambique: enfrentando a crise iminente. Boletim Informativo, Maputo, v.4, n.11, maio/ago. 1994. [mimeografado] 